\title{
The Extended Burr XII Distribution with Variable Shapes for the Hazard Rate
}

\author{
T. H. M. Abouelmagd \\ Management Information System Department, Taibah \\ University, Saudi Arabia \\ Department of Statistics, Mathematics and Insurance \\ Benha University, Egypt \\ tabouelmagd@taibahu.edu.sa \\ M. S. Hamed \\ Management Information System Department, Taibah \\ University, Saudi Arabia \\ Department of Statistics, Mathematics and Insurance \\ Benha University, Egypt \\ moswilem@gemail.com
}

\author{
Ahmed Z. Afify \\ Department of Statistics, Mathematics and Insurance \\ Benha University, Egypt \\ ahmed.afify@fcom.bu.edu.eg
}

\begin{abstract}
We define and study a new continuous distribution called the exponentiated Weibull Burr XII. Its density function can be expressed as a linear mixture of Burr XII. Its hazard rate is very flexibile in accomodating various shapes including constant, decreasing, increasing, J-shape, unimodal or bathtub shapes. Various of its structural properties are investigated including explicit expressions for the ordinary and incomplete moments, generating function, mean residual life, mean inactivity time and order statistics. We adopted the maximum likelihood method for estimating the model parameters. The flexibility of the new family is illustrated by means of a real data application.
\end{abstract}

Keywords: Burr XII Distribution, Exponentiated Weibull-H family, Generating Function, Maximum Likelihood.

\section{Introduction}

The statistical literature contains many generalized distributions which extensively used in modeling data in various applied areas such as reliability, insurance and life testing. The Burr-XII (BXII) distribution, proposed by Burr (1942), has many generalized forms in the literature such as the beta BXII distribution studied by Paranaíba et al. (2011), the Kumaraswamy BXII distribution introduced by Paranaíba et al. (2013), the beta exponentiated BXII distribution defined by Mead (2014), the Marshall-Olkin extended BXII distribution due to Al-Saiarie et al. (2014), the McDonald BXII distribution proposed by Gomes et al. (2015), the exponentiated Burr XII Poisson distribution due to da Silva et al. (2015), the Weibull BXII (WBXII) distribution studied by Afify et al. 
(2017), the odd Lindley BXII distribution due to Abouelmagd et al. (2017) and the Kumaraswamy exponentiated BXII distribution defined by Mead and Afify (2017).

In this paper, we define and study a new five-parameter model named the exponentiated Weibull Burr XII (EWBXII) distribution which extends the WBXII distribution (Afify et al., 2017) and provide greater flexibility in modelling data. Based on the exponentiated Weibull-H (EW-H) family proposed by Cordeiro et al. (2017), we construct our newly model.

Consider the bsaeline cumulative distribution function (CDF) $H(x ; \xi)$ with parameter vector $\xi$. Then, the CDF of the EW-H family is given by

$$
F(x ; v, a, b, \xi)=\left\{1-\exp \left[-a\left(\frac{H(x ; \xi)}{1-H(x ; \xi)}\right)^{b}\right]\right\}^{v}
$$

The probability density function (PDF) of the EW-H family is

$$
\begin{aligned}
& f(x ; v, a, b, \xi)=a b v h(x ; \xi) \frac{H(x ; \xi)^{b-1}}{[1-H(x ; \xi)]^{b+1}} \exp \left[-a\left(\frac{H(x ; \xi)}{1-H(x ; \xi)}\right)^{b}\right] \\
& \times\left\{1-\exp \left[-a\left(\frac{H(x ; \xi)}{1-H(x ; \xi)}\right)^{b}\right]\right\}^{v-1},
\end{aligned}
$$

where $v, a$ and $b$ are three additional positive shape parameters which provide greater flexibility in accommodating all forms of the hazard rate function (HRF).

The EWBXII distribution is a flexible model which exhibit all forms of the hazard rate function (HRF) as shown in Figure 2. Further, the EWBXII distribution contains seventeen sub-models as special cases.

The rest of the paper is outlined as follows. In Section 2, we define the EWBXII distribution, present its special models and provide some plots of its PDF and HRF. In Section 3, we derive a linear representation for the EWBXII PDF and obtain some of its mathematical properties including ordinary and incomplete moments, mean residual life, mean inactivity time, moment generating function (mgf) and order statistics. In Section 4, we use maximum likelihood to estimate the model parameters. In Section 5, we use a real data set to prove empirically the flexibility of the new model. Finally, some concluding remarks are given in Section 6.

\section{The EWBXII distribution}

In this section, we define the EWBXII distribution, provide its special cases and give some plots for its PDF and HRF.

The CDF and PDF of the two parameter BXII distribution are given by (for $x>0$ )

$$
H(x ; \alpha, \beta)=1-\left(1+x^{\alpha}\right)^{-\beta} \quad \text { and } \quad h(x ; \alpha, \beta)=\alpha \beta x^{\alpha-1}\left(1+x^{\alpha}\right)^{-\beta-1} \text {, }
$$

respectively, where $\alpha$ and $\beta$ are positive shape parameters. 
By inserting the CDF of the BXII in equation (1), we obtain the CDF of the EWBXII distribution

$$
F(x)=\left(1-\exp \left\{-a\left[\left(1+x^{\alpha}\right)^{\beta}-1\right]^{b}\right\}\right)^{v}, x>0
$$

and the corresponding PDF of (3) is given by

$$
\begin{aligned}
& f(x)=\operatorname{abv} \alpha \beta x^{\alpha-1} \frac{\left[1-\left(1+x^{\alpha}\right)^{-\beta}\right]^{b-1}}{\left(1+x^{\alpha}\right)^{-\beta b+1}} \exp \left\{-a\left[\left(1+x^{\alpha}\right)^{\beta}-1\right]^{b}\right\} \\
& \times\left(1-\exp \left\{-a\left[\left(1+x^{\alpha}\right)^{\beta}-1\right]^{b}\right\}\right)^{v-1},
\end{aligned}
$$

where $\alpha, \beta, a, b$ and $v$ are positive shape parameters which can provide more flexibility to model various real world data.

Plots of the PDF and HRF of the EWBXII distribution are displayed in Figures 1 and 2, respectively. The plots in Figure 1 show that the PDF of the EWBXII distribution can be reversed J-shape, right-skewed, left-skewed, symmetric or concave down. Figure 2 shows that the HRF of the proposed model can be constant, decreasing, increasing, J-shape, unimodal, bathtub shapes.

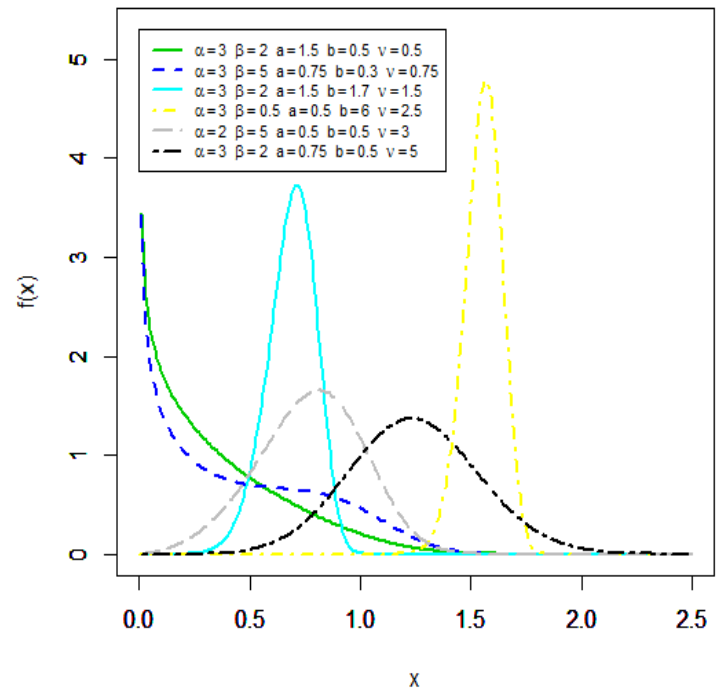

(a)

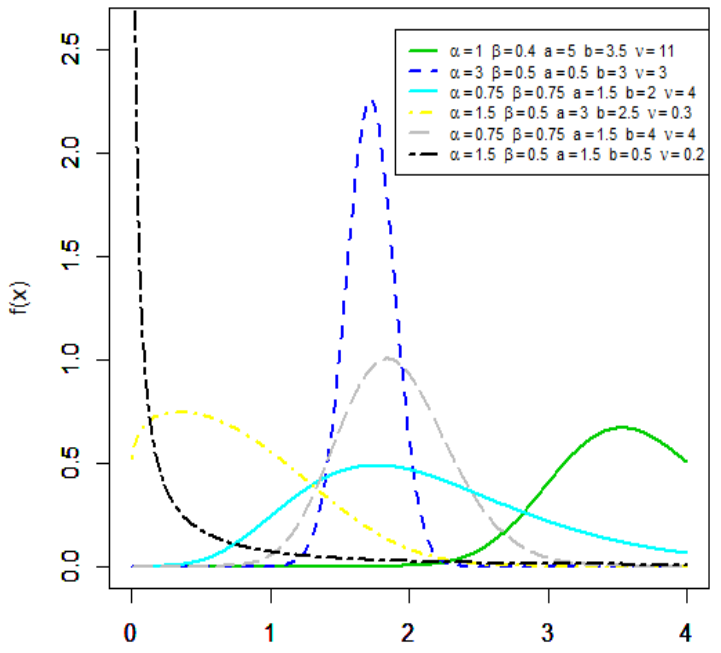

$X$
(b)

Figure 1: Some possible shapes for the EWBXII PDF 


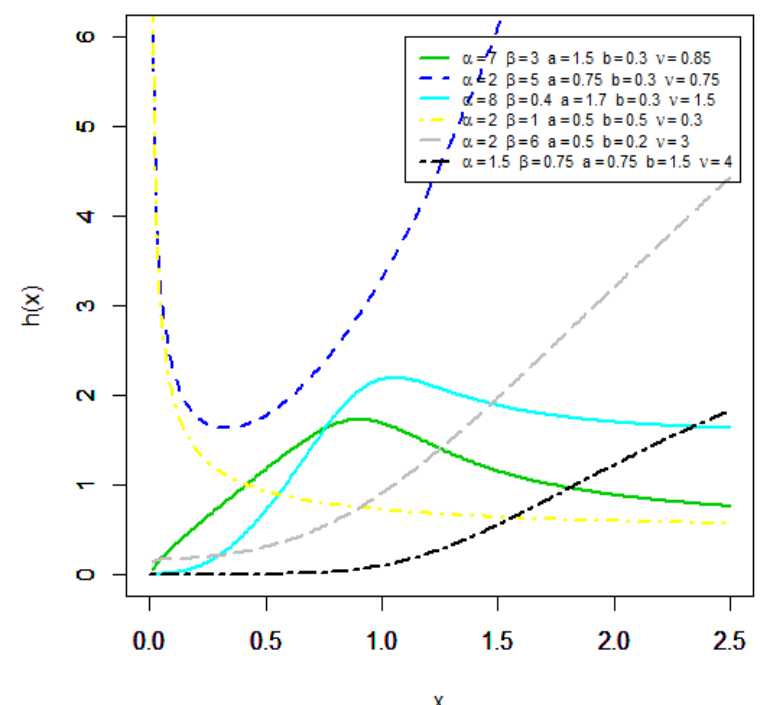

(a)

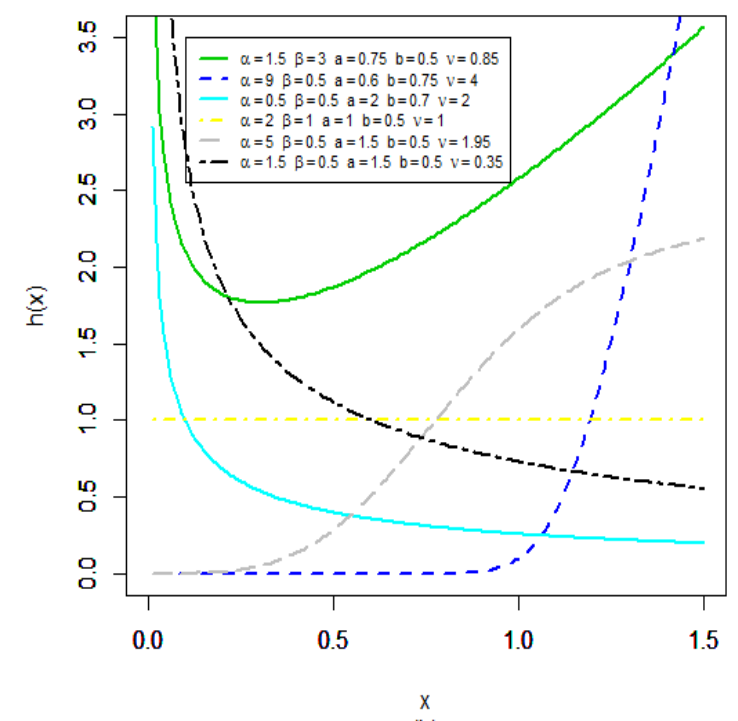

(b)

Figure 2: Some possible shapes for the EWBXII HRF

The EWBXII distribution is a comprehensive distribution which contains several lifetime models, such as Weibull BXII, exponential BXII (ExBXII), odd generalized exponential BXII (OGEx-BXII), Burr X BXII (BX-BXII), BXII, Lomax (Lo) and log logistic (LL) distributions as special cases. Table 1 provides all sub-models of the EWBXII distribution.

Table 1: Special cases of the EWBXII Distribution

\begin{tabular}{|c|l|c|c|c|c|c|c|}
\hline No. & Model & $\alpha$ & $\beta$ & $a$ & $b$ & $v$ & Author \\
\hline 1 & WBXII & $\alpha$ & $\beta$ & $a$ & $b$ & 1 & Afify et al. (2017) \\
\hline 2 & W Lomax & 1 & $\beta$ & $a$ & $b$ & 1 & - \\
\hline 3 & W log-logistic & $\alpha$ & 1 & $a$ & $b$ & 1 & - \\
\hline 4 & Ex BXII & $\alpha$ & $\beta$ & $a$ & 1 & 1 & - \\
\hline 5 & Ex Lomax & 1 & $\beta$ & $a$ & 1 & 1 & - \\
\hline 6 & Ex log-logistic & $\alpha$ & 1 & $a$ & 1 & 1 & - \\
\hline 7 & EW Lomax & 1 & $\beta$ & $a$ & $b$ & $v$ & New \\
\hline 8 & EW log-logistic & $\alpha$ & 1 & $a$ & $b$ & $v$ & New \\
\hline 9 & OGEx-BXII & $\alpha$ & $\beta$ & $a$ & 1 & $v$ & New \\
\hline 10 & OGEx-Lomax & 1 & $\beta$ & $a$ & 1 & $v$ & New \\
\hline 11 & OGEx-log-logistic & $\alpha$ & 1 & $a$ & 1 & $v$ & New \\
\hline 12 & BX-BXII & $\alpha$ & $\beta$ & 1 & 2 & $v$ & New \\
\hline 13 & BX- Lomax & 1 & $\beta$ & 1 & 2 & $v$ & New \\
\hline 14 & BX- log-logistic & $\alpha$ & 1 & 1 & 2 & $v$ & New \\
\hline 15 & BXII & $\alpha$ & $\beta$ & 1 & 1 & 1 & Burr (1942) \\
\hline 16 & Lomax & 1 & $\beta$ & 1 & 1 & 1 & - \\
\hline 17 & Log-logistic & $\alpha$ & 1 & 1 & 1 & 1 & - \\
\hline
\end{tabular}




\section{Some EWBXII properties}

Some properties of the EWBXII distribution including ordinary and incomplete moments, generating function, mean residual life (MRL), mean inactivity time (MIT) and order statistics are derived in this section.

\subsection{Linear representation}

According to equation (4.5) in Cordeiro et al. (2017), the PDF of the EWBXII distribution can be rewritten as

$$
\begin{aligned}
f(x) & =\sum_{i, k, j=0}^{\infty} \frac{(-1)^{k+i} v b a^{k+1}(i+1)^{k} \Gamma(v) \Gamma([k+1] b+j+1)}{i ! k ! j ! \Gamma(v-i) \Gamma([k+1] b+1)} \\
& \times \alpha \beta x^{\alpha-1}\left(1+x^{\alpha}\right)^{-\beta-1}\left[1-\left(1+x^{\alpha}\right)^{-\beta}\right]^{(k+1) b+j-1} .
\end{aligned}
$$

Applying the generalized binomial expansion to the last term, we have

$$
f(x)=\sum_{m=0}^{\infty} \phi_{m} g_{\beta(m+1)}(x) \text {, }
$$

where the constant term is given by

$$
\phi_{m}=\sum_{i, k, j=0}^{\infty} \frac{(-1)^{k+i+m} v b a^{k+1}(i+1)^{k} \Gamma(v) \Gamma([k+1] b+j) \Gamma([k+1] b+j+1)}{i ! k ! j !(m+1) ! \Gamma(v-i) \Gamma([k+1] b+1) \Gamma([k+1] b+j-m)}
$$

and $g_{\beta(m+1)}(x)$ refer to the BXII PDF with parameters $\alpha$ and $\beta(m+1)$. Equation (5) is important in deriving some properties of the EWBXII distributions from those of the BXII distribution.

\subsection{Moments}

The $r$ th ordinary moment of $X$, follows from (5) (for $\alpha \beta(m+1)>r)$ as

$$
\mu_{r}^{\prime}=\sum_{m=0}^{\infty} \phi_{m} \beta(m+1) B\left(\beta(m+1)-\frac{r}{\alpha}, \frac{r}{\alpha}+1\right)
$$

The mean of $X$ follows by setting $r=1$ in the above equation.

The $r$ th incomplete moment of the EWBXII distribution follows from (5) as

$$
\varphi_{r}(t)=\sum_{m=0}^{\infty} \phi_{m} \beta(m+1) B\left(t^{\alpha} ; \beta(m+1)-\frac{r}{\alpha}, \frac{r}{\alpha}+1\right) .
$$


When $\boldsymbol{r}=\mathbf{1}$, we have the first incomplete moment of $\boldsymbol{X}$

$$
\varphi_{1}(t)=\sum_{m=0}^{\infty} \phi_{m} \beta(m+1) B\left(t^{\alpha} ; \beta(m+1)-\frac{1}{\alpha}, \frac{1}{\alpha}+1\right)
$$

which is important to calculate the Bonferroni and Lorenz curves and the MRL and MIT.

The MRL or life expectancy at age $t$ is defined by

Using $\varphi_{1}(t)$, we obtain

$$
m_{X}(t)=\frac{1-\varphi_{1}(t)}{1-F(t)}-t
$$

$$
m_{X}(t)=\frac{1}{1-F(t)} \sum_{m=0}^{\infty} \phi_{m} \beta(m+1) B\left(t^{\alpha} ; \beta(m+1)-\frac{1}{\alpha}, \frac{1}{\alpha}+1\right)-t
$$

The MIT is defined (for $t>0$ ) by

$$
M_{X}(t)=t-\frac{\varphi_{1}(t)}{F(t)}
$$

By inserting $\varphi_{1}(t)$ in the above equation, we have the MIT of $X$ as

$$
M_{X}(t)=t-\frac{1}{F(t)} \sum_{m=0}^{\infty} \phi_{m} \beta(m+1) B\left(t^{\alpha} ; \beta(m+1)-\frac{1}{\alpha}, \frac{1}{\alpha}+1\right) .
$$

The mgf of $X$ follows from (5) as

$$
M_{X}(t)=\sum_{m=0}^{\infty} \phi_{m} M_{\beta(m+1)}(t),
$$

where $M_{\beta(m+1)}(t)$ is the mgf of the BXII distribution with two parameters $\alpha$ and $\beta(m+1)$. Paranaíba et al. (2011) provided a simple formula for the mgf of BXII distribution with two-parameter $\alpha$ and $\beta$ (for $t<0$ ) as

$$
M(t)=s I\left(-t, \frac{s}{\beta}-1, \frac{s}{\beta},-\beta-1\right) .
$$

Combining equations (6) and (7), the mgf of $X$ reduces to

$$
M_{X}(t)=s \sum_{m=0}^{\infty} \phi_{m} I\left(-t, \frac{s}{\beta(m+1)}-1, \frac{s}{\beta(m+1)},-\beta(m+1)-1\right) .
$$




\subsection{Order statistics}

Let $X_{1}, \ldots, X_{n}$ be a random sample of size $n$ from the EWBXII distribution and let $X_{(1)}, \ldots, X_{(n)}$ be the corresponding order statistics. Then, the pdf of the $i$ th order statistic, $X_{i: n}$, is given by

$$
f_{i: n}(x)=\frac{n ! f(x)}{(i-1) !(n-i) !} \sum_{j=0}^{n-i}(-1)^{j}\left(\begin{array}{c}
n-i \\
j
\end{array}\right) F(x)^{j+i-1}
$$

Based on equation (6.2) in Cordeiro et al. (2017), we have

$$
\begin{aligned}
f(x) F(x)^{j+i-1} & =\sum_{l, k, m=0}^{\infty} \frac{(-1)^{l+k} v b a^{k+1}(l+1)^{k} \Gamma([j+i] v) \Gamma([k+1] b+m+1)}{l ! k ! m ! \Gamma([j+i] v-l) \Gamma([k+1] b+1)} \\
& \times \alpha \beta x^{\alpha-1}\left(1+x^{\alpha}\right)^{-\beta-1}\left[1-\left(1+x^{\alpha}\right)^{-\beta}\right]^{(k+1) b+m-1}
\end{aligned}
$$

Using the generalized binomial expansion, the last equation reduces to

$$
\begin{aligned}
& f(x) F(x)^{j+i-1}=\sum_{l, k, m, s=0}^{\infty} \frac{(-1)^{l+k+s} v b a^{k+1}(l+1)^{k} \Gamma([j+i] v) \Gamma([k+1] b+m)}{l ! k ! m ! s ! \Gamma([j+i] v-l) \Gamma([k+1] b+1)} \\
& \times \frac{\Gamma([k+1] b+m+1)}{\Gamma([k+1] b+m-s)} \alpha \beta x^{\alpha-1}\left(1+x^{\alpha}\right)^{-\beta(s+1)-1} \text {. }
\end{aligned}
$$

Substituting the last equation in equation (8), the pdf of $X_{i: n}$ comes out as

$$
f_{i: n}(x)=\sum_{\mathrm{s}=0}^{\infty} t_{s} g_{\beta(s+1)}(x)
$$

where

$$
\begin{gathered}
t_{s}=\frac{n !}{(i-1) !(n-i) !} \sum_{l, k, m, s=0}^{\infty} \sum_{j=0}^{n-i} \frac{(-1)^{j+l+k+s} v b a^{k+1}(l+1)^{k}}{l ! k ! m ! s !(s+1) \Gamma([j+i] v-l)}\left(\begin{array}{c}
n-i \\
j
\end{array}\right) \\
\times \frac{\Gamma([j+i] v) \Gamma([k+1] b+m) \Gamma([k+1] b+m+1)}{\Gamma([k+1] b+1) \Gamma([k+1] b+m-s)}
\end{gathered}
$$

and $g_{\beta(s+1)}(x)$ as before is the BXII PDF with parameters $\alpha$ and $\beta(s+1)$.

Based on equation (9), the $r$ th moment of $X_{i: n}$ reduces to

$$
E\left(X_{i: n}^{r}\right)=\sum_{s=0}^{\infty} t_{s} \beta(s+1) B\left(\beta(s+1)-\frac{r}{\alpha}, \frac{r}{\alpha}+1\right)
$$

\section{Estimation}

In this section, the unknown parameters of the EWBXII model are estimated via the maximum likelihood from complete samples. Consider a random sample of size $n$, 
$x_{1}, \ldots, x_{n}$, is drawn from the EWBXII distribution with parameter vector $\theta=$ $(\alpha, \beta, a, b, v)^{T}$. Then, the log-likelihood for the EWBXII distribution comes out as

$$
\begin{gathered}
\ell=n \log (\alpha \beta a b v)+(\alpha-1) \sum_{i=1}^{n} \log x_{i}+(\beta b-1) \sum_{i=1}^{n} \log s_{i} \\
+(b-1) \sum_{i=1}^{n} \log \left(1-\mathrm{s}_{i}{ }^{-\beta}\right)-a \sum_{i=1}^{n} d_{i}{ }^{b} \\
+(v-1) \sum_{i=1}^{n} \log \left[1-\exp \left(-a d_{i}{ }^{b}\right)\right]
\end{gathered}
$$

where $\mathrm{s}_{i}=1+x_{i}^{\alpha}$ and $d_{i}=\mathrm{s}_{i}^{\beta}-1$.

The score vector elements, $\boldsymbol{U}(\theta)=\frac{\partial \ell}{\partial \theta}=(U(\alpha), U(\beta), U(a), U(b), U(v))^{T}$, are given by

$$
\begin{aligned}
& U(\alpha)=\frac{n}{\alpha}+\sum_{i=1}^{n} \log x_{i}-a b \sum_{i=1}^{n} \frac{t_{i} d_{i}^{b-1}}{s_{i}{ }^{-2 \beta}}+(\beta b-1) \sum_{i=1}^{n} \frac{x_{i}{ }^{\alpha} \log x_{i}}{s_{i}} \\
& +(b-1) \sum_{i=1}^{n} \frac{t_{i}}{1-s_{i}{ }^{-\beta}}+a b(v-1) \sum_{i=1}^{n} \frac{\frac{t_{i} d_{i}{ }^{b-1}}{\mathrm{~s}_{i}{ }^{2 \beta}} \exp \left(-a d_{i}{ }^{b}\right)}{1-\exp \left(-a d_{i}{ }^{b}\right)}, \\
& U(\beta)=\frac{n}{\beta}+b \sum_{i=1}^{n} \log s_{i}-a b \sum_{i=1}^{n} d_{i}^{b-1} \mathrm{~s}_{i}{ }^{\beta} \log s_{i}-(b-1) \sum_{i=1}^{n} \frac{\mathrm{s}_{i}{ }^{\beta} \log \mathrm{s}_{i}}{1-\mathrm{s}_{i}^{-\beta}} \\
& +a b(v-1) \sum_{i=1}^{n} \frac{d_{i}^{b-1} s_{i}{ }^{\beta} \log s_{i} \exp \left(-a d_{i}{ }^{b}\right)}{1-\exp \left(-a d_{i}^{b}\right)} \\
& U(a)=\frac{n}{a}-\sum_{i=1}^{n} d_{i}^{b}+(v-1) \sum_{i=1}^{n} \frac{d_{i}^{b} \exp \left(-a d_{i}^{b}\right)}{1-\exp \left(-a d_{i}^{b}\right)^{\prime}} \\
& U(b)=\frac{n}{b}+\beta \sum_{i=1}^{n} \log s_{i}+\sum_{i=1}^{n} \log \left(1-\mathrm{s}_{i}{ }^{-\beta}\right)-a \sum_{i=1}^{n} d_{i}{ }^{b} \log d_{i} \\
& +(v-1) \sum_{i=1}^{n} \frac{a d_{i}^{b} \exp \left(-a d_{i}^{b}\right) \log d_{i}}{1-\exp \left(-a d_{i}^{b}\right)}
\end{aligned}
$$

and

$$
U(v)=\frac{n}{v}+\sum_{i=1}^{n} \log \left[1-\exp \left(-a d_{i}^{b}\right)\right]
$$

Respectively, where $t_{i}=\beta x_{i}^{\alpha} \mathrm{s}_{i}^{-\beta-1} \log x_{i}$.

The estimate of the unknown parameters can be obtained by setting the score vector to zero, $\mathbf{U}(\hat{\theta})=0$. We can get the MLEs $\hat{\alpha}, \hat{\beta}, \hat{a}, \hat{b}$ and $\hat{v}$ by solving the above system of 
equations simultaneously using numerically method with iterative techniques such as the Newton-Raphson algorithm.

\section{Data analysis}

In this section, we illustrate the flexibility and importance of the EWBXII distribution using a real data set. The data refer to nicotine measurements, made from several brands of cigarettes in 1998, collected by the Federal Trade. This data set contains $n=346$ observations.

We shall compare the fit of the EWBXII distribution with some other competitive distributions, namely: the WBXII and beta BXII (Paranaíba et al., 2011), additive Weibull (AW) (Xie and Lai, 1995), beta Weibull (BW) (Lee et al., 2007), transmuted Weibull Lomax (TWL) (Afify et al., 2015), Kumaraswamy Marshall-Olkin Fréchet (KMOF) (Afify et al., 2016) and BXII distributions. The PDFs of these models are given by

WBXII: $f(x)=a b \alpha \beta x^{\alpha-1} \frac{\left[1-\left(1+x^{\alpha}\right)^{-\beta}\right]^{b-1}}{\left(1+x^{\alpha}\right)^{-\beta b+1}} \exp \left\{-a\left[\left(1+x^{\alpha}\right)^{\beta}-1\right]^{b}\right\}, \alpha>0, \beta>$ $0, a>0$ and $b>0$.

BBXII: $f(x)=\frac{c \theta \beta^{-c}}{B(a, b)} x^{c-1}\left[1+\left(\frac{x}{\beta}\right)^{c}\right]^{-\theta b-1}\left\{1-\left[1+\left(\frac{x}{\beta}\right)^{c}\right]^{-\theta}\right\}^{a-1}, \theta>0, \beta>0, a>$ $0, c>0$ and $b>0$.

AW: $f(x)=\left(\alpha \delta x^{\delta-1}+\gamma \beta x^{\beta-1}\right) e^{-\alpha x^{\delta}-\gamma x^{\beta}}, \alpha>0, \beta>0, \gamma>0$ and $\delta>0$.

BW: $f(x)=\frac{\beta \alpha^{\beta}}{B(a, b)} x^{\beta-1} e^{-b(\alpha x)^{\beta}}\left[1-e^{-(\alpha x)^{\beta}}\right]^{a-1}, \alpha>0, \beta>0, a>0$ and $b>0$.

TWL: $f(x)=\frac{a b \alpha}{\beta}\left(1+\frac{x}{\beta}\right)^{b \alpha-1} \exp \left\{-a\left[\left(1+\frac{x}{\beta}\right)^{\alpha}-1\right]^{\mathrm{b}}\right\}$ $\times\left[1-\left(1+\frac{x}{\beta}\right)^{-\alpha}\right]^{b-1}\left\{1-\lambda+2 \lambda e^{-a\left[\left(1+\frac{x}{\beta}\right)^{\alpha}-1\right]^{b}}\right\}, \quad \alpha>0, \beta>0, a>0, b>$ 0 and $|\lambda| \leq 1$.

$\mathrm{KMOF}: f(x)=\alpha \beta a b \delta^{\beta} x^{-\beta-1} \exp \left[-a\left(\frac{\delta}{x}\right)^{\beta}\right]\left\{\alpha+(1-\alpha) \exp \left[-\left(\frac{\delta}{x}\right)^{\beta}\right]\right\}^{-a-1}$

$$
\begin{gathered}
\times\left\{1-\exp \left[-a\left(\frac{\delta}{x}\right)^{\beta}\right]\left\{\alpha+(1-\alpha) \exp \left[-\left(\frac{\delta}{x}\right)^{\beta}\right]\right\}^{-a}\right\}^{b-1}, \alpha>0, \beta>0, a>0, b \\
>0 \text { and } \delta>0 .
\end{gathered}
$$

The Akaike information criterion $(A I C)$, consistent Akaike information criterion $(C A I C)$, Bayesian information criterion $(B I C)$, Hannan-Quinn information criterion $(H Q I C)$ and $-\hat{\ell}$, where $\hat{\ell}$ is the maximized log-likelihood, are used for comparing the fitted models.

Tables 2 and 4 list the values of $-\hat{\ell}, A I C, C A I C, B I C$ and $H Q I C$ whereas the MLEs and their corresponding standard errors (in parentheses) of the model parameters are given in Tables 3 and 5. 
Table 2: Goodness-of-fit statistics

\begin{tabular}{|l|c|c|c|c|c|}
\hline \multicolumn{1}{|c|}{ Model } & $-\hat{\ell}$ & AIC & CAIC & BIC & HQIC \\
\hline EWBXII & 106.709 & 223.419 & 223.595 & 242.651 & 231.077 \\
\hline BBXII & 107.856 & 225.712 & 225.888 & 244.945 & 233.371 \\
\hline WBXII & 112.289 & 232.579 & 232.697 & 247.965 & 238.706 \\
\hline BW & 112.587 & 233.173 & 233.29 & 248.559 & 239.300 \\
\hline AW & 113.291 & 234.581 & 234.698 & 249.966 & 240.707 \\
\hline TWL & 112.916 & 235.832 & 236.009 & 255.064 & 243.491 \\
\hline KMOF & 114.034 & 238.068 & 238.244 & 257.299 & 245.726 \\
\hline BXII & 127.294 & 258.587 & 258.622 & 266.280 & 261.651 \\
\hline
\end{tabular}

Table 3: MLEs and their SEs (in parentheses)

\begin{tabular}{|c|c|c|c|c|c|}
\hline Model & \multicolumn{5}{|c|}{ Estimates } \\
\hline $\begin{array}{l}\text { EWBXII } \\
(\alpha, \beta, a, b, v)\end{array}$ & $\begin{array}{c}2.0186 \\
(0.3822)\end{array}$ & $\begin{array}{l}11.4275 \\
(3.3495)\end{array}$ & $\begin{array}{c}2.0765 \\
(0.9761)\end{array}$ & $\begin{array}{c}0.0869 \\
(0.0425)\end{array}$ & $\begin{array}{c}24.1274 \\
(23.1607)\end{array}$ \\
\hline $\begin{array}{l}\text { BBXII } \\
(a, b, c, \beta, k)\end{array}$ & $\begin{array}{c}0.2086 \\
(0.0148)\end{array}$ & $\begin{array}{c}0.7285 \\
(0.2535)\end{array}$ & $\begin{array}{l}10.4641 \\
(0.1915)\end{array}$ & $\begin{array}{c}1.1101 \\
(0.0483)\end{array}$ & $\begin{array}{c}0.9449 \\
(0.3098)\end{array}$ \\
\hline $\begin{array}{l}\text { WBXII } \\
(\alpha, \beta, a, b)\end{array}$ & $\begin{array}{c}0.7219 \\
(0.2658)\end{array}$ & $\begin{array}{c}2.1971 \\
(0.8762)\end{array}$ & $\begin{array}{c}0.0339 \\
(0.0527)\end{array}$ & $\begin{array}{c}2.7275 \\
(1.3047)\end{array}$ & \\
\hline $\begin{array}{l}\mathrm{BW} \\
(\alpha, \beta, a, b)\end{array}$ & $\begin{array}{l}0.6686 \\
(0.578)\end{array}$ & $\begin{array}{l}3.1645 \\
(0.426)\end{array}$ & $\begin{array}{l}0.7784 \\
(0.163)\end{array}$ & $\begin{array}{l}3.0922 \\
(8.174)\end{array}$ & \\
\hline $\begin{array}{l}\mathrm{AW} \\
(\alpha, \beta, \gamma, \delta)\end{array}$ & $\begin{array}{c}1.135 \\
(0.062)\end{array}$ & $\begin{array}{c}0.3084 \\
(0.1)\end{array}$ & $\begin{array}{c}0.0002 \\
\left(1.369 \times 10^{-3}\right)\end{array}$ & $\begin{array}{l}2.7219 \\
(0.114)\end{array}$ & \\
\hline $\begin{array}{l}\text { TWL } \\
(\alpha, \beta, a, b, \lambda)\end{array}$ & $\begin{array}{c}7.8903 \\
(15.497)\end{array}$ & $\begin{array}{l}17.1065 \\
(44.562) \\
\end{array}$ & $\begin{array}{c}3.8175 \\
(4.1843) \\
\end{array}$ & $\begin{array}{l}2.3499 \\
(0.309) \\
\end{array}$ & $\begin{array}{l}0.1600 \\
(0.214) \\
\end{array}$ \\
\hline $\begin{array}{l}\text { KMOF } \\
(\alpha, \beta, \delta, a, b)\end{array}$ & $\begin{array}{c}20410.35 \\
(137.2224) \\
\end{array}$ & $\begin{array}{c}1.1973 \\
(0.0109) \\
\end{array}$ & $\begin{array}{c}0.0109 \\
(0.0009) \\
\end{array}$ & $\begin{array}{c}2.2892 \\
(0.0667) \\
\end{array}$ & $\begin{array}{r}36699.16 \\
(12799.87) \\
\end{array}$ \\
\hline $\begin{array}{l}\text { BXII } \\
(\alpha, \beta)\end{array}$ & $\begin{array}{c}3.4865 \\
(0.1539)\end{array}$ & $\begin{array}{c}1.8087 \\
(0.0973)\end{array}$ & & & \\
\hline
\end{tabular}

In Table 2, we compare the fits of the EWBXII distribution with the BBXII, WBXII, BW, AW, TWL, KMOF and BXII distributions. One can see, from Table 1, that the EWBXII distribution has the lowest values for goodness-of-fit statistics among all fitted models. So it could be chosen as the best model for the nicotine data.

The histogram and the estimated densities for nicotine data are displayed in Figure 3. These plots reveal that the EWBXII distribution is the best model to fit this data set. The fitted PDF, CDF, survival function (SF) and Q-Q plots of the EWBXII distribution are shown in Figure 4. 


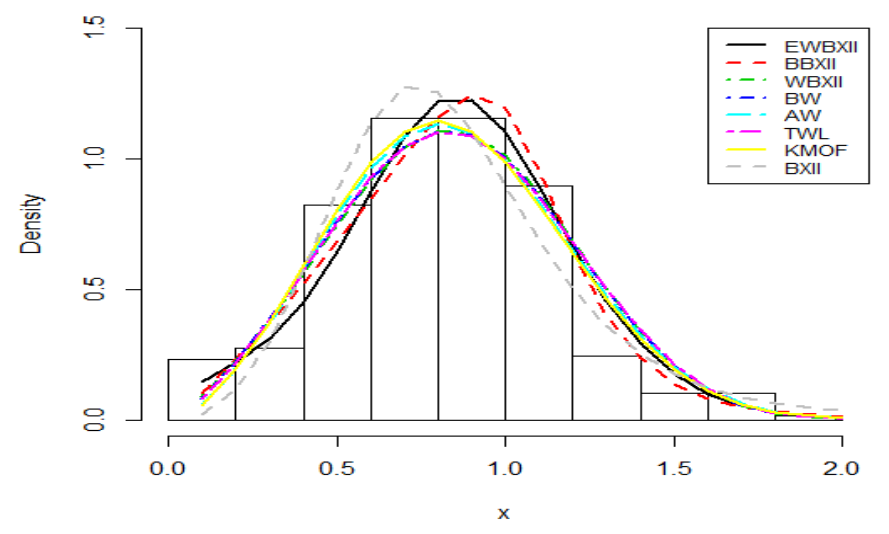

Figure 4: Fitted PDF of the EWBXII distribution and other fitted PDFs
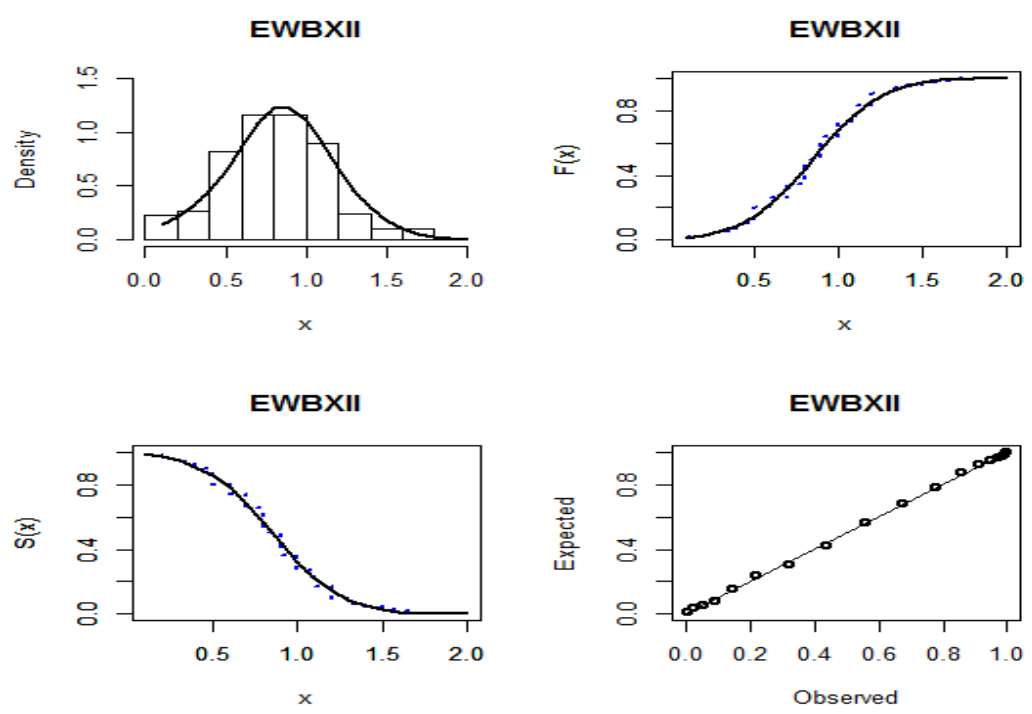

Figure 5: Fitted PDF, CDF, SFand Q-Q plots of the EWBXII distribution

\section{Conclusions}

We study a new five-parameter model called the exponentiated Weibull Burr XII (EWBXII) distribution which generalizes the two-parameter Burr XII distribution and .... We provide some mathematical properties of the new family including explicit expansions for the ordinary and incomplete moments, quantile and generating functions and entropies. The maximum likelihood estimation of the model parameters is investigated. By means of a real data application, we show that the EWBXII distribution can provide better fit than some other well-known models.

\section{References}

1. Abouelmagd, T. H. M., Al-mualim, S., Afify, A. Z., Ahmad, M. and Al-Mofleh, H. (2017). The odd Lindley Burr XII distribution with applications. Pakistan Journal of Statistics, forthcoming. 
2. Afify, A. Z., Cordeiro, G. M., Ortega, E. M. M., Yousof, H. M. and Butt, N. S. (2017). The four-parameter Burr XII distribution: properties, regression model and applications. Communications in Statistics-Theory and Methods, forthcoming.

3. Afify, A. Z., Nofal, Z. M., Yousof, H. M., El Gebaly, Y. M. and Butt, N. S. (2015). The transmuted Weibull Lomax distribution: properties and application. Pak. J. Stat. Oper. Res., 11, 135-152.

4. Afify, A. Z., Yousof, H. M., Cordeiro, G. M., Nofal, Z. M. and Ahmad, M. (2016). The Kumaraswamy Marshall-Olkin Fréchet distribution with applications. Journal of ISOSS, 2, 41-58.

5. Al-Saiari, A. Y., Baharith, L. A. and Mousa, S. A. (2014). Marshall-Olkin extended Burr type XII distribution. International Journal of Statistics and Probability,3, 78-84.

6. Burr, I. W. (1942). Cumulative frequency functions. Annals of Mathematical Statistics, 13, 215-232.

7. Cordeiro, G. M., Afify, A. Z., Yousof, H. M., Pescim, R. R. and Aryal, G. R. (2017). The exponentiated Weibull-H family of distributions: theory and applications. Mediterr. J. Math., 14:155.

8. da Silva, R. V., Gomes-Silva, F., Ramos, M. W. A. and Cordeiro, G. M. (2015). The exponentiated Burr XII Poisson distribution with application to lifetime data. International Journal of Statistics and Probability, 4, 112-131.

9. Gomes, A. E., da-Silva, C. Q. and Cordeiro, G. M. (2015). Two extended Burr models: Theory and practice. Communication in Statistics Theory - Methods, 44, 1706-1734.

10. Lee, C., Famoye, F., and Olumolade, O. (2007). Beta-Weibull distribution: some properties and applications to censored data. Journal of modern applied statistical methods, 6, 17.

11. Mead, M. E. (2014). The beta exponentiated Burr XII distribution. Journal of Statistics: Advances in Theory and Applications,12, 53-73

12. Mead, M. E. and Afify, A. Z. (2017). On five parameter Burr XII distribution: properties and applications. South African Statistical Journal, 51, 67 -80.

13. Paranaíba, P. F., Ortega, E. M. M., Cordeiro, G. M. and de Pascoa, M. (2013). The Kumaraswamy Burr XII distribution: theory and practice. Journal of Statistical Computation and Simulation, 83, 2117-2143.

14. Paranaíba, P. F., Ortega, E. M. M., Cordeiro, G. M. and Pescim, R. R. (2011). The beta Burr XII distribution with application to lifetime data. Computation Statistics and Data Analysis, 55, 1118-1136.

15. Xie, M. and Lai, C. D. (1995). Reliability analysis using an additive Weibull model with bathtub-shaped failure rate function. Reliability Engineering and System Safety, 52, 87-93. 